\title{
Ensino, Inovação e Produção de Software: O uso da prática reflexiva
}

\author{
Aline Andrade1, Regina Fabia Albuquerque ${ }^{1}$, Tania Mara Dors ${ }^{1}$, Fabio Binder ${ }^{1}$, \\ Andreia Malucelli ${ }^{1}$, Sheila Reinehr ${ }^{1}$ \\ ${ }^{1}$ Programa de Pós-graduação em Informática (PPGIa) - Pontifícia Universidade Católica \\ do Paraná (PUCPR) - Rua Imaculada Conceição, 1155 - Curitiba - Paraná \\ aline.sarah@pucpr.edu.br, \{regina.fabia, tania.dors, fabio.binder, \\ andreia.malucelli, sheila.reinehr\}@pucpr.br
}

Resumo. O mercado de computação exige profissionais que tenham não apenas as habilidades técnicas, como também as comportamentais. A PUCPR e a Apple estabeleceram um ateliê de software cujo objetivo é capacitar desenvolvedores para gerar aplicações móveis, utilizando o método Challenge Based Learning (CBL) e a prática reflexiva. O objetivo desta pesquisa foi compreender as contribuições da prática reflexiva no desenvolvimento de competências profissionais, por meio de estudo de caso, utilizando entrevistas semiestruturadas e ciclos de codificação da Grounded Theory. Os resultados demonstram que os estudantes desenvolveram habilidades valiosas para a prática profissional de engenheiro de software.

\begin{abstract}
The computing market demands professionals who have not only technical but also behavioral skills. PUCPR and Apple have established a software studio whose objective is to train developers to generate mobile applications using the Challenge Based Learning (CBL) method and the reflective practice. This research aimed to understand the contributions of reflective practice in developing professional competencies through a case study, using semi-structured interviews and Grounded Theory coding cycles. The results demonstrate that students developed valuable skills for software engineer professional practice.
\end{abstract}

A Apple Developer Academy (Academy) é um projeto de inovação tecnológica, parceria entre a Apple e a PUCPR, que busca oferecer uma formação completa ao estudante, possibilitando, com base em suas ideias, aprender a desenvolver e publicar aplicativos. Por meio de metodologias de aprendizagem ativa, como o Challenge Based Learning (CBL) e a prática reflexiva, a Academy instiga os estudantes a desenvolver suas próprias habilidades. O ambiente é um ateliê de software voltado para a resolução de problemas sob orientação de professores capacitados que dão feedbacks formais e informais aos desenvolvedores (BULL; WHITLE, 2014; ROSCA, 2018).

A presença e a importância da prática reflexiva são reconhecidas na literatura educacional da Engenharia de Software. Trata-se de uma forma de aprendizagem baseada em reflexões, como o próprio nome diz, que abrange desde questionamentos constantes, trabalho em equipe, revisão por pares, aprendizado colaborativo e resolução de problemas em grupo (BULL; WHITLE, 2014; DORS ET AL., 2020). O conceito foi proposto por Schön (1983) ao observar ateliês de arquitetura, conceituando termos como: reflexão em ação, reflexão sobre a ação e conversa com o material. A prática 
reflexiva na arquitetura demonstrou ser um método eficaz no auxílio do desenvolvimento de soft skills, melhorando o desempenho e auxiliando os estudantes a adquirir um talento artístico essencial para as competências profissionais (SCHÖN, 1983; HAZZAN, 2002). As contribuições na área da tecnologia são descritas por Dors (2019) no que se refere ao desenvolvimento de habilidades técnicas e atitudinais do engenheiro de software. Com tantos resultados positivos voltados para o ensino do desenvolvimento de aplicativos móveis neste ateliê de software, surge o interesse em aprofundar a compreensão sobre os resultados proporcionados pelo uso da prática reflexiva, estendendo o estudo de Dors et al. (2020) para a análise de um conjunto mais amplo de estudantes e projetos em turma subsequente à analisada por Dors et al. (2020).

Foi realizado um estudo de caso, com coleta de dados via entrevistas semiestruturadas realizadas de janeiro a maio/2021. Devido à pandemia da COVID-19, elas ocorreram de forma remota e síncrona com duração de 30 a 60 minutos. Participaram estudantes maiores de 18 anos que tinham finalizado o curso na Academy no ano anterior e que haviam utilizado o $\mathrm{CBL}$ e a prática reflexiva. $\mathrm{O}$ roteiro semiestruturado foi inicialmente desenvolvido pela entrevistadora (estudante) e revisado pela orientadora e colaboradores. No primeiro ciclo foram entrevistados 10 estudantes e no segundo, mais 8. Todas as entrevistas foram gravadas mediante autorização do entrevistado e transcritas para análise. A análise utilizou práticas da Grounded Theory (codificação aberta e axial) e teve o apoio da ferramenta Atlas.ti.

A partir das análises, foi possível observar o desenvolvimento de competências técnicas (hard skills): aprendizado de tecnologias, gerenciamento de projetos, comunicação escrita e até mesmo aprimoramento do inglês. Foram também observadas competências pessoais (soft skills): saber ouvir os colegas, liderança (tomada de decisão), trabalho em equipe (que envolve interação com os colegas, colaboração e gerência de conflitos), melhora do comportamento, melhoria contínua do estudante, melhoria do aprendizado e autoconhecimento (confiança). Esses resultados confirmam e estendem os encontrados por Dors (2020). Resultados completos em Andrade (2021).

\section{Referências}

Andrade, A.; Albuquerque, R.; Dors, T.; Binder, F.; Malucelli, A.; Reinehr, S. Ensino, Inovação e Produção de Software: o Uso da Prática Reflexiva. XX Simpósio Brasileiro de Qualidade de Software, 2021.

Bull, C.; Whittle, J. (2014). Supporting reflective practice in software engineering education through a studio-based approach. IEEE Software, v.31, n.4, p. 44-50.

Dors, T.M.; Van Amstel, F.M.C; Binder, F.; Reinehr, S.; Malucelli, A. Reflective Practice in Software Development Studios: Findings from an Ethnographic Study. In 2020 IEEE 32nd Conference on Software Engineering Education and Training (CSEE\&T).

Hazzan, O. (2002) The reflective practitioner perspective in software engineering education. Journal of Systems and Software, v. 63, n. 3, p. 161-171.

Rosca, D. (2018). Acquiring professional software engineering skills through studio-based learning. 17th International Conference on Information Technology based Higher Education and Training, (ITHET'18). Olhao, Portugal, pp. 1-6.

Schön, D. (1983) The reflective practitioner: how professionals think in action. $1^{\text {st }}$ Ed., San Francisco, CA, US: Jossey-bass. Engenharia de Requisitos 